\title{
Porous Diamond Grinding Wheels on Ceramic Binders: Design and Manufacturing
}

\author{
János Kundrák ${ }^{1}$, Dmitri O. Fedorenko², Vladimir A. Fedorovich ${ }^{2}$, Elena Y. Fedorenko ${ }^{2}$, Evgeni V. Ostroverkh ${ }^{2}$ \\ ${ }^{1}$ Institute of Manufacturing Science, University of Miskolc, Egyetemváros H-3515 Miskolc, Hungary. E-mail: \\ kundrak@uni-miskolc.hu \\ ${ }^{2}$ National Technical University "Kharkiv Polytechnic Institute", Ukraine. E-mail: dmitriy_fedorenko@ukr.net, \\ fedvlad49@gmail.com, fedorenko_e@ukr.net,evgostr401@gmail.com
}

An approach to increasing the efficiency of the diamond grinding of hard-working materials is shown. A wellfounded choice of characteristics of the diamond-bearing layer of the tool can be made through analyzing the results of 3D modeling of the processes of formation and operation of the diamond-bearing layer and stresses upon it. Diamond wheels formed on porous ceramic binders are investigated and discussed.

Keywords: diamond grinding wheel, porous vitreous binder, development and design, production and operation, finite element method

\section{Introductions}

Grinding with diamond wheels is the most efficient way of machining parts from various materials. Issues related to improving the efficiency of diamond abrasive processing, due to their relevance, are of increasing interest for manufacturers and consumers of diamond-abrasive tools. One of the ways to improve the effectiveness of grinding is the creation and use of a highly porous tool, since an increase of the wheel porosity creates more favorable conditions for the intensive cutting of materials with a reduction in the defectiveness of surface quality of the machined parts.

The presence of large pores ensures the placement of shavings between grains and contributes to additional cooling of the workpiece due to the acceleration of the penetration of the coolant into the cutting zone. As a result of lowering the temperature in the cutting zone, the processing capacity can be increased by $2-2.5$ times due to forcing the cutting mode [1-2].

Thus, as indicated in [3], the use of grinding wheels made of porous diamond makes it possible to reduce the temperature in the grinding zone by $1.5-2.1$ times up to $300-500{ }^{\circ} \mathrm{C}$, which is well below the threshold of diamond thermal destruction.

The main advantages of porous grinding tools are:

- increased metal removal per unit time and shortening of the grinding cycle;

- $\quad$ simplicity of profiling and increase in tool life due to a significant reduction in the frequency of dressing;

- $\quad$ significant reduction in the risk of burns due to the high permeability of the diamond-bearing layer;

- reduction of residual stresses after grinding.

This opens up prospects for the use of porous diamond wheels for operations where the maximum contact zone of the diamond-bearing layer with the detail takes place (for example, in deep and flat grinding or grinding gear teeth, especially for materials that are sensitive to overheating and are hard to work).
Currently, high-porosity grinding wheels are made mainly of white electrocorundum grade $25 \mathrm{~A}$, chromotitanium electrocorundum grade $91 \mathrm{~A}$, or silicon carbide $64 \mathrm{C}$. The creation of diamond wheels with an open structure (No. 10-12) will allow the realization of the above possibilities of porous grinding tools and take advantage of synthetic diamond used as an abrasive material.

For the production of porous diamond wheels, it is expedient to use a ceramic binder, which allows a diamondbearing layer to be produced with a given porosity and makes it possible to create favorable conditions for the self-sharpening of the tool and to shorten the processing time [4].

The experience of using ceramic bindings indicates that compared with metal and polymer binders they exhibit maximum temperature stability and can be used in dry grinding without the use of coolant. With ceramic binder it is possible to create a diamond abrasive tool with high porosity and self-sharpening ability. Such a tool is most effective in semi-finishing and finishing operations as well as in deep grinding, with high-speed modes, as it provides processing without burns with increased feed rates and cutting depths [5-7]. Currently, wheels with ceramic binder are widely used in all types of machine part grinding and are the most effective tool in mass production for internal, external, flat and incision grinding $[5,8]$.

However, it should be noted that the typical ceramic binders used in the manufacture of the grinding tool are of little use for the manufacture of diamond wheels, since sintering of the diamond-bearing layer with their use occurs at a temperature of $750{ }^{\circ} \mathrm{C}$ and higher $[9,10]$. As is known, the main disadvantage of synthetic diamond used as an abrasive material its low temperature resistance: an increase in temperature to $700-750{ }^{\circ} \mathrm{C}$, in particular in using fine-grained diamond powder, causes the destruction of grains $[11,12]$. It should also be taken into account that the temperature that occurs in the cutting zone when grinding hard-to-work materials can exceed $800{ }^{\circ} \mathrm{C}$.

Therefore, the main condition for the production of porous diamond wheels on ceramic binders is a decrease in the sintering temperature of the diamond-bearing layer and a decrease in the temperatures arising during grinding 
in the cutting zone. This problem can be achieved by forming the porous structure of the diamond-bearing layer at a reduced temperature (up to $650{ }^{\circ} \mathrm{C}$ ) using low-melting ceramic binders.

One of the conditions for obtaining high-quality porous diamond-abrasive tools is to ensure a uniform distribution of grains. In this regard, the choice of the rational structure of the diamond wheel with a given porosity and uniform grain distribution during the design stage of the tool will allow higher metal removal rates, reduce the risk of burning, improve the chip removal conditions and increase the service life of the tool.

Realization of the advantages of ceramic-matrix diamond wheels with a given porosity is possible provided that the composition and structure of the diamond-bearing layer are properly selected, as along with the justified choice of the grinding mode. The methodology of 3D modeling [13] based on the finite element method used in this work allows the design of high-cost diamond wheels to be automated and includes the following stages:

- modelling the process of forming a diamond layer to determine the conditions that ensure the integrity of diamond grains;

- simulation of the grinding process to determine the rational conditions for processing materials of different groups in the mode of self-sharpening;

- three-dimensional study of the parameters of the relief of the working surface of the diamond wheel by laser scanning;

- development of an expert system for determining the rational characteristics of diamond wheels and modes of grinding hard-to-work materials.

To carry out these tasks the software packages COSMOS, ANSYS ${ }^{\circledR}$ Mechanical, NOSTRAN, and "LSDYNA" were used.

In order to determine the rational characteristics of the diamond-bearing layer of porous wheels and the conditions for conducting the processes of formation of the diamond-bearing layer and grinding in the self-sharpening regime, the effect of porosity of the binder, temperature and strength loads on the level and nature of the distribution of stresses arising during sintering of the diamondbearing layer and the grinding of different groups materials (on an example of a hard alloy VK8, sitall AS-418 and synthetic polycrystalline diamonds (SPCD)) were investigated.

Fig. 1 presents models designed to study the stressstrain state of the "metal-phase-diamond grain-binderpore" system, which simulates the structural-phase features of the porous diamond wheel at the micro level. 3D models differed in the content of arbitrarily oriented closed pores with a size of 50-100 microns. In imitation models, diamond grains of the brand $\mathrm{AC}$ with a grain size of $125 / 100$ are modeled as octahedra. Inclusions of the metal-solvent $\mathrm{Fe}_{95} \mathrm{Si}_{5}$ in the amount of 6 vol. \% (hereinafter, the metal phase) is represented in the form of randomly arranged rectangular parallelepipeds. Concentration of grains was set as a percentage of the volume of the binder and the total volume of grains $(25 \%, 50 \%, 100 \%)$ and was performed by decreasing the inter-grain distance in the model. The binder was created in the form of prismatic fragments. The characteristics of the binder corresponded to the properties of a typical ceramic binder K1-01; the porosity of the binder was varied between $15-50 \%$.

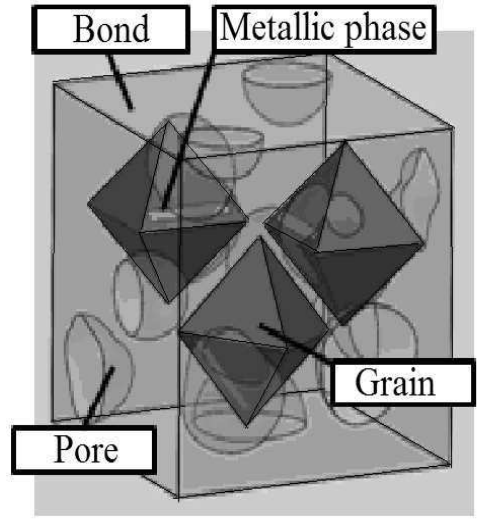

$a$

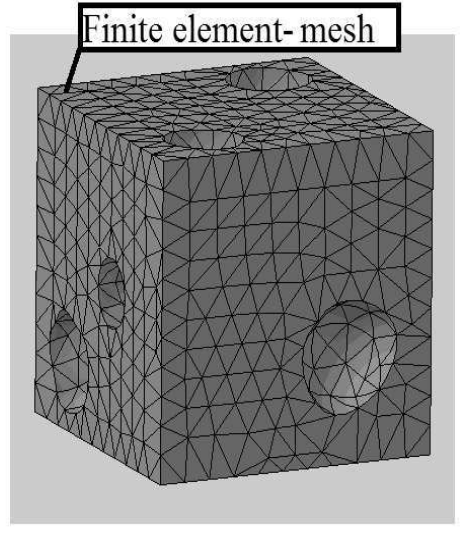

$b$

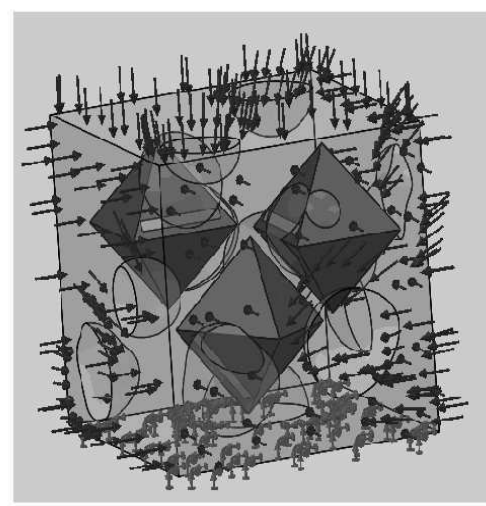

$c$

Fig. $13 D$ micro-level models of porous diamond wheel

Temperature and strength loads were assigned proceeding from the conditions for conducting the processes of formation of the diamond-bearing layer and grinding [1416].

Analysis of the stress-strain state of systems was carried out on the basis of the results of finite element calculations and their visualization. To determine the rational characteristics and conditions for the formation of a diamond-bearing layer of porous wheels, as well as the processing parameters of materials of different groups in the self-sharpening mode, the influence of the porosity of the binder, temperature and force loads that imitate the sintering and grinding processes on the level and nature of stress distribution was investigated. 


\section{Influence of diamond-bearing layer sintering parameters on the stress-strain state of the "metal-phase-diamond grain-binder-pore" system}

As is known, the diamond-bearing layer of wheels on the ceramic binder is obtained in two ways depending on

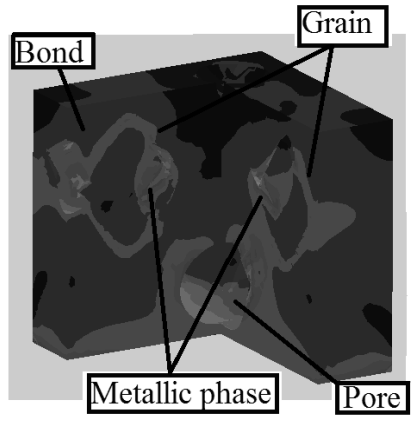

$a$

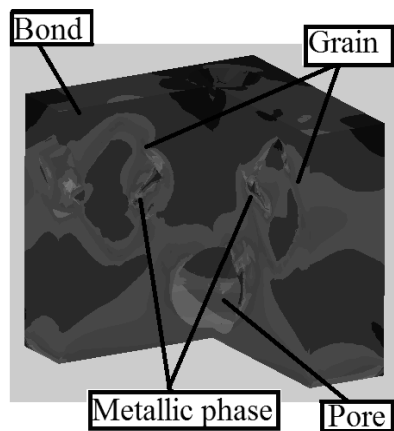

$b$ the given porosity:

- hot pressing (for wheels with dense and medium structure from 1 to 7 );

- free sintering (for wheels with open, highly porous structure from 8 to 12 ).

Fig. 2 Influence of the temperature and strength loads on the level and pattern of equivalent stresses occurring in the sintering zone of the diamond-bearing layer on the temperature: a) $400^{\circ} \mathrm{C}$; b) $600{ }^{\circ} \mathrm{C}$; c) $800{ }^{\circ} \mathrm{C}$

Taking into account the conditions for the formation of the diamond-bearing layer, the sintering temperature was varied within $400-800{ }^{\circ} \mathrm{C}$; compaction pressure - varied in the range of $30-50 \mathrm{MPa}$.

Calculations showed that the level of stresses caused only by increasing the pressure to $50 \mathrm{MPa}$ at the sintering temperature to $400{ }^{\circ} \mathrm{C}$ does not exceed the ultimate strength of the grains AC $125 / 100\left(\sigma_{\text {str }}=0.2 \mathrm{GPa}\right)$, which indicates an insignificant effect of the strength factor. The stresses arising during the formation of the diamond-bearing layer of the tool are characterized by a characteristic distribution pattern (Fig. 2): the maximum equivalent stresses $\left(\sigma_{\mathrm{eq}}\right)$ are localized at the sites of inclusion of the metal phase in the grain and distributed along the contour of the sphere inscribed in the octahedron.

When the temperature is raised to $600{ }^{\circ} \mathrm{C}$ or more the stresses in the region of inclusions of the metal-phase increase and exceed this critical level. This is explained by the significant difference in the CTE of the metalphase and diamond, and also by the structural heteroge- neity of the latter. Due to a noticeable expansion of inclusions of the metal-phase in the grains during the sintering of the diamondiferous layer, it is likely that they will be partially destroyed already at the stage of tool manufacture.

\section{Effect of the porosity of the diamond-bearing layer on the stress-strain state of the "metal- phase-diamond grain-binder-pore" system}

The beneficial effect of a decrease in the volume content of abrasive grains is known to occur through an increase in the porosity of the grinding tool on the thermodynamic intensity of the grinding process [5, 16-18].

Information on the nature of the effect of the porosity of the diamond-bearing layer on the integrity of diamond grains during sintering is extremely limited. It can be seen from the data obtained by us (Fig. 3) that when the binder porosity increases, a redistribution of stresses occurs during the sintering of the diamondiferous layer.

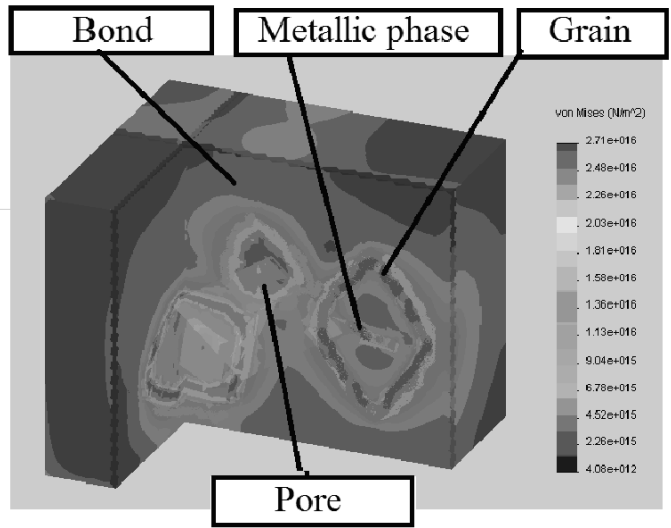

$a$

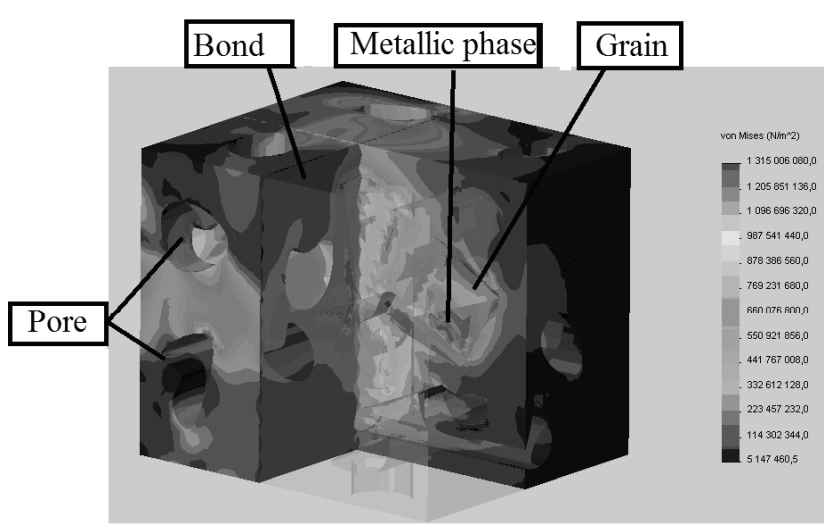

$b$

Fig. 3 Stress distribution during diamondiferous layer sintering: a) with a porosity of $5 \%$ : b) with a porosity of $30 \%$ 
Thus, in the case of a diamondiferous layer with 100 $\%$ grain concentration and natural porosity up to $5 \%$, stress on grains at a sintering temperature of $700{ }^{\circ} \mathrm{C}$ and a compaction pressure of $30 \mathrm{MPa}$ reaches $0.762 \mathrm{GPa}$ and is distributed predominantly on the contact surface of grains and binder. In this case the grain volume in which the stresses exceed the ultimate AC $125 / 100\left(\sigma_{\text {str }}=0.2 \mathrm{GPa}\right)$ strength of the grain reaches $20-23 \%$. If the bond porosity is increased to $30 \%$ the equivalent stress is reduced to $40 \%$. The grain volume for which stress is higher than 0.2 GPa does not exceed $15 \%$.

Moreover, the region of maximum stresses propagation also encompasses the peripheral sections of the binder in which the pores are located. This is most likely due to the peculiarities of redistribution of heat-sensitive loads in a material with increased porosity.

Calculations also showed that the stress-strain state of the system under study during sintering of the diamondbearing layer is largely determined by grain concentration in the porous binder and also by its thermo-physical characteristics. It has been established that with an increase in the grain concentration to $100 \%$, the level of equivalent stresses increases approximately three-fold. This fact is probably due to the approaching of grains, fixed in the binder, which causes the superposition of the stress fields of neighboring grains and manifests itself in an increase in the overall stress level.

In this case, the centers of critical stresses exceeding the strength of grains are localized on the faces of the octahedron which imitates the diamond grain. The results showed that in terms of grain integrity during sintering their concentration in the diamondiferous layer when using coarse diamond powders (100/80 $\mu \mathrm{m}$ and more) should not exceed $50 \%$. With an increase in CTE and thermal conductivity of binder there is a marked increase in stress levels with all other conditions kept unchanged and this tendency increases with increasing of diamondiferous layer sintering temperature. This indicates the importance of considering the complex thermo-physical

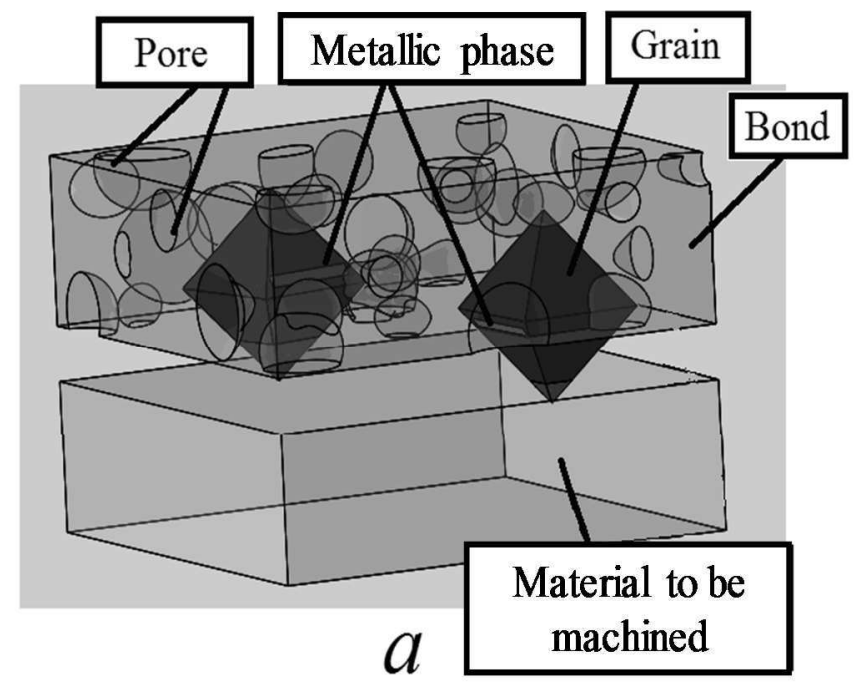

characteristics and the need to reduce the sintering temperature of the diamondiferous layer of the tool when choosing a binder.

It has been established that when diamond-containing composites are sintered at temperatures above $600^{\circ} \mathrm{C}$, the probability of destruction of low-grade diamond grains (AC2, AC4, AC6) is high, which necessitates the application of protective coatings. Increasing the porosity of the diamondiferous layer to $30 \mathrm{vol}$. \% and above reduces this probability and eliminates the need for an additional technological operation of the metallization of diamond grains.

Carrying out a series of simulation experiments using mathematical planning methods made it possible to determine the optimal characteristics of the binder to ensure the integrity of the grains at the stage of manufacturing the diamond-bearing layer of the tool: thermal conductivity $\lambda=0.6-0.75 \mathrm{~W} / \mathrm{m} \cdot \mathrm{K}$, CTE $(6-7) \cdot 10^{-6} \mathrm{~K}^{-1}$, the elastic modulus $\mathrm{E}=95-110 \mathrm{GPa}$, the shear modulus $\mathrm{G}=(35-$ $45) \cdot 10^{3} \mathrm{MPa}$.

\section{Effect of the binder properties and porosity on the ability of a diamond-abrasive tool to self- sharpen during the grinding of different groups of materials grinding}

To model the grinding process by porous wheels, the binder properties recommended at the previous stage of the research were used as the initial data. Within the framework of this experiment, the porosity of the diamondiferous layer $\left(\mathrm{P}_{\mathrm{V}}=20 \%, 50 \%\right)$ and the concentration of grains in it were varied $\left(\mathrm{C}_{\mathrm{gr}}=25 \%, 50 \%, 100 \%\right)$.

As the treated material, a sitall AS-418 strainer, VK8 hard alloy and synthetic polycrystalline diamonds (SPCD) were considered. The implementation of the simulation experiment was carried out using a series of developed 3D models of the diamond-bearing layer. Illustrations of the distribution of stresses in the diamondiferous layer when grinding sitall AS-418 are shown in Fig. 4.

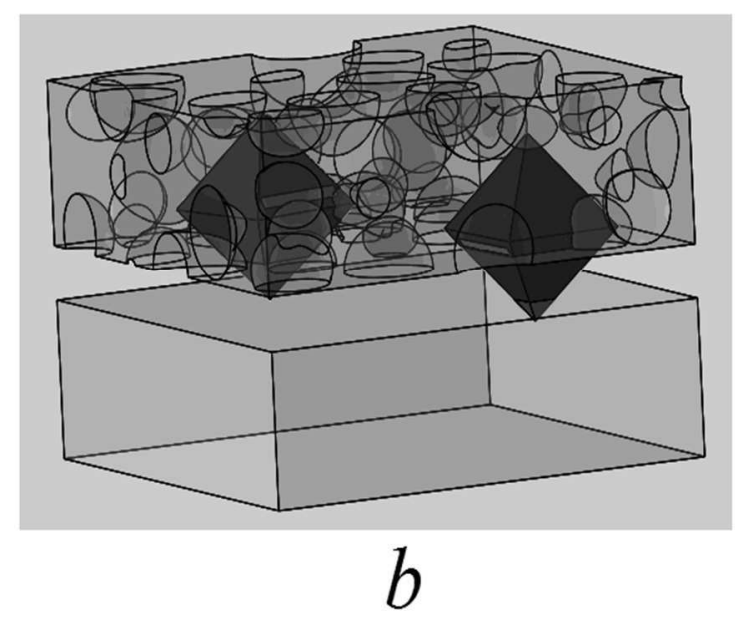



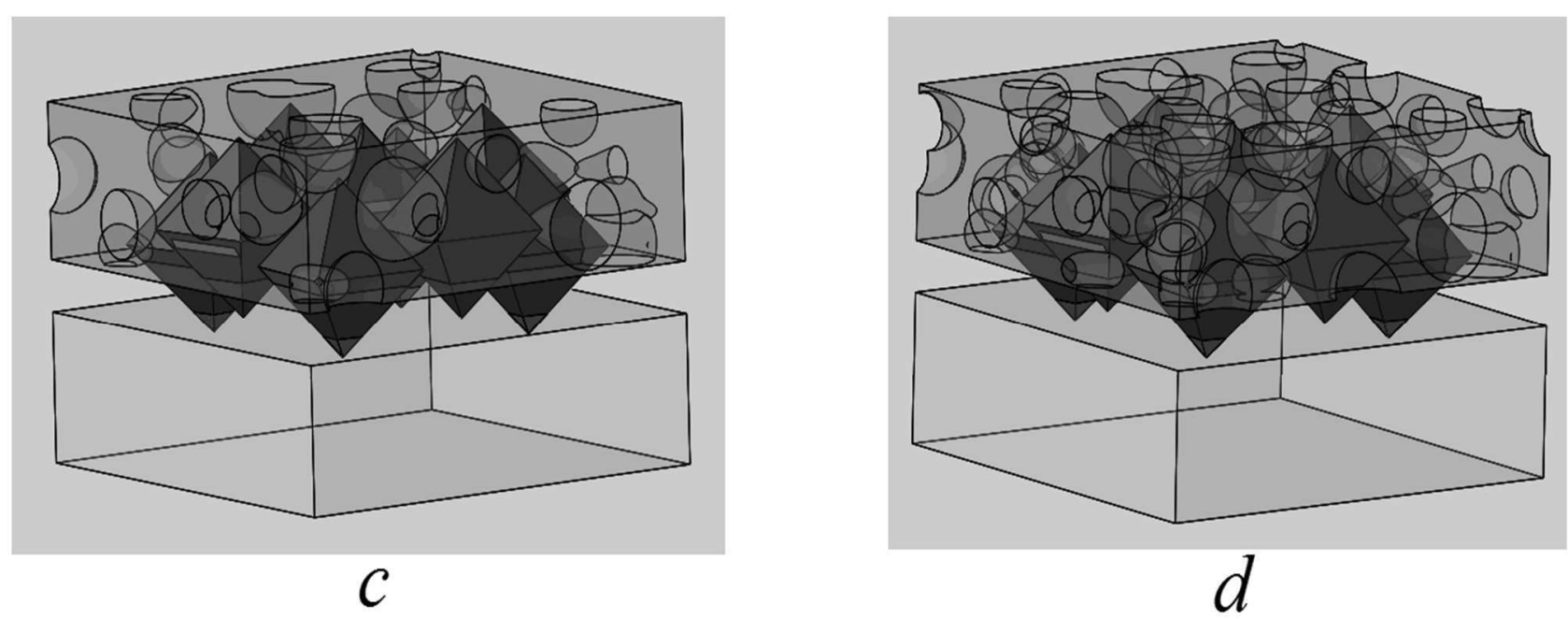

Fig. $43 \mathrm{D}$ models of diamond wheels with different porosity and grain concentration: a) $P V=25 \%$; $C g r=25 \%$; b) $P V=50 \%$; $C g r=25 \%$; c) $P V=25 \%$; $C g r=100 \%$; d) $P V=50 \%$; $C g r=100 \%$

Analysis of the distribution of stresses showed that in a diamond wheel with a more porous structure, the maximum equivalent stresses arising during grinding are localized both at the contact of the grains with the binder and around the pores. In this case, the presence of additional stresses on the contacts of the pores and binder does not affect the overall level of maximum stresses (Fig. 5). With an increase in the concentration of grains and the porosity of the diamondiferous layer, the dimensions of such sites increase significantly; the maximum stresses are manifested not only directly on the working surface of the wheel, but also in its internal regions at a distance of $\sim 100 \mu \mathrm{m}$ from the working surface. Calculations showed that with an increase in the concentration of grains in the wheel, the level of the stresses arising increases markedly. At $100 \%$ concentration of grains for all values of diamondiferous layer porosity, the stress level exceeds the strength of the grains AC6 125/100. This fact indicates an increase in the probability of the significant loss of grains during grinding. This phenomenon, known in the practice of grinding as "involuntary self-sharpening", can largely reduce the tool's efficiency and diamond-abrasive processing performance.

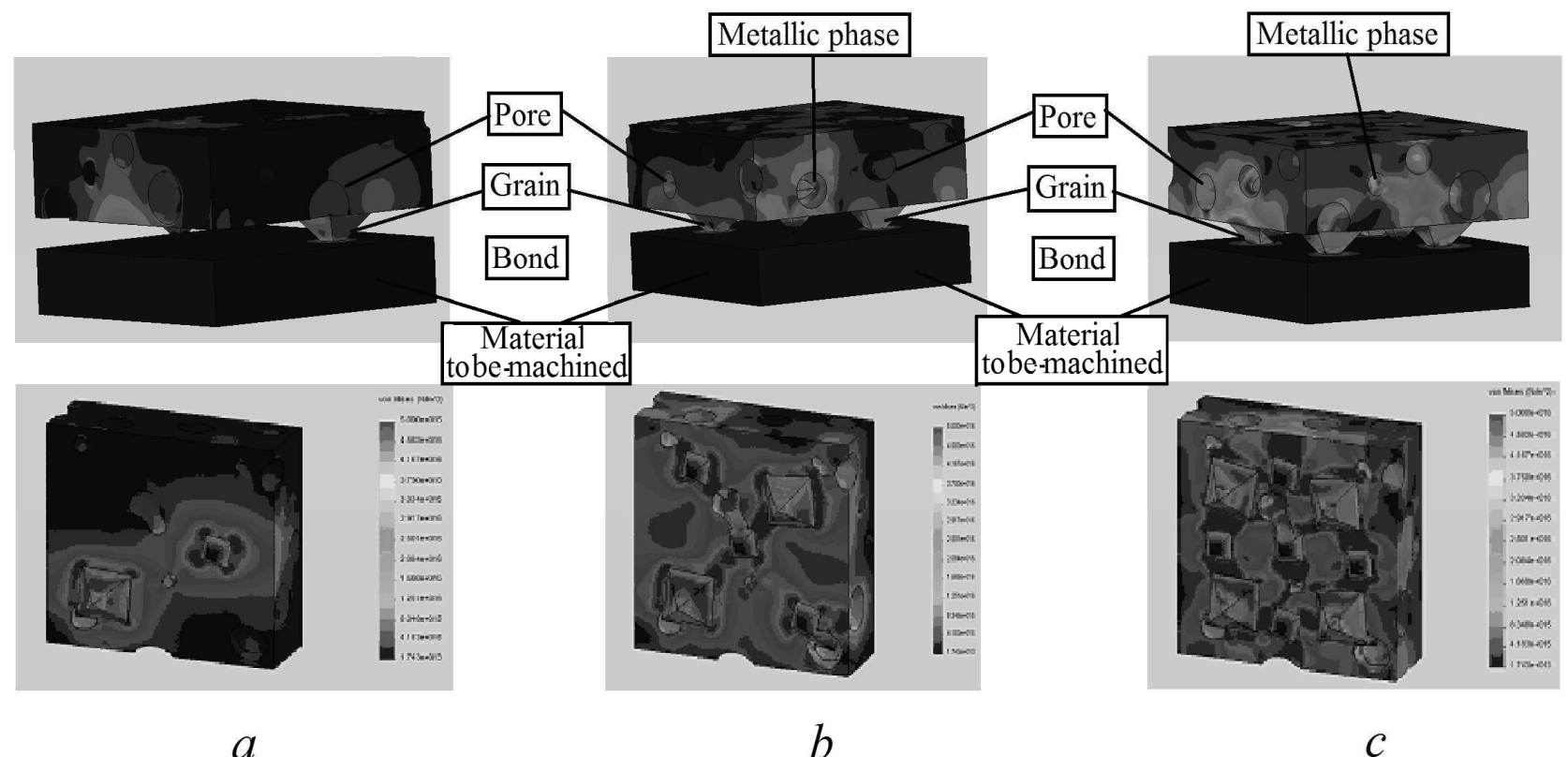

Fig. 5 Stresses distribution during grinding sitall $A S-418$ with a porous diamond wheel $\left(P_{V}=25 \%\right)$ with different grain concentrations: a) $C_{g r}=20 \%$; b) $C_{g r}=50 \%$; c) $C_{g r}=100 \%$

With a decrease in the concentration of AC 125/100 grains to $50 \%$, the stresses causing their destruction $\left(\sigma_{\mathrm{eq}}>0.2 \mathrm{GPa}\right)$ arise at the contact areas of grains and the processed material (for all materials studied) only in a diamondiferous layer with $50 \%$ porosity (Fig. 6). This fact is explained by the rise in the load on a unit grain, as a result of which the probability of microdamage of blunted diamonds during grinding increases as one of the conditions for efficient self-sharpening of diamond wheels. 


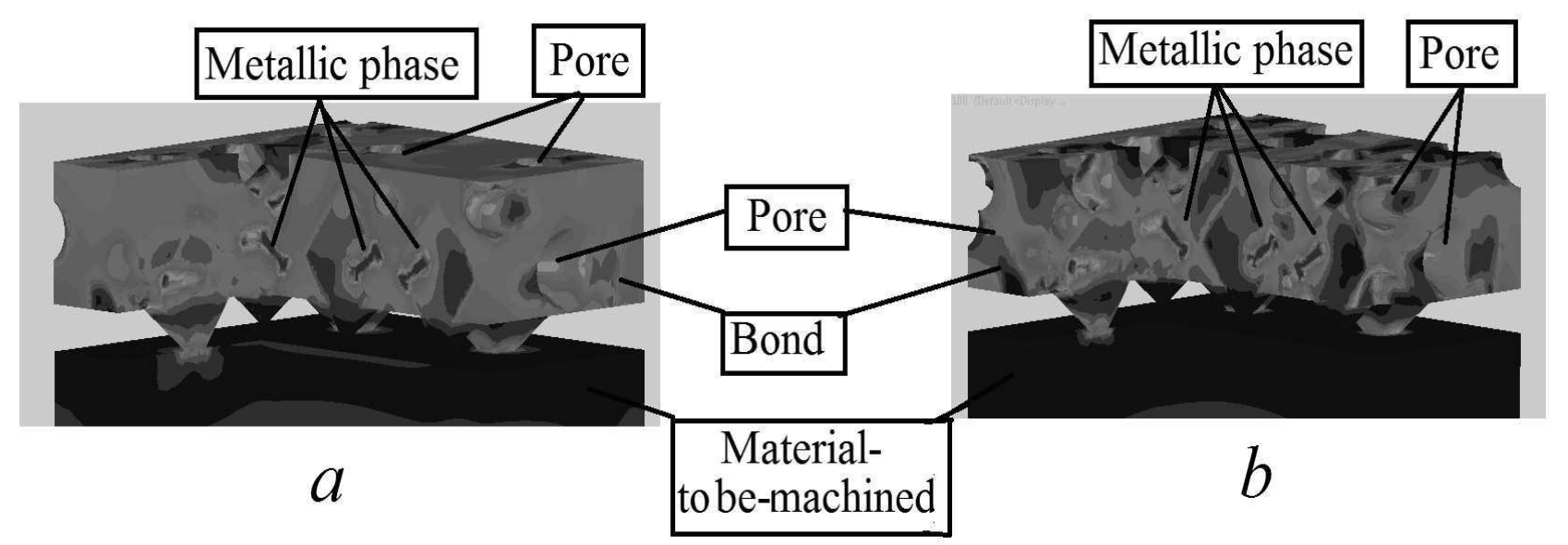

Fig. 6 Diagrams of stress distribution during grinding of hard alloy VK8 porous diamond wheels: a) $P_{V}=15 \%$, $C_{g r}=50$ $\%$; b) $P_{V}=30 \%, C_{g r}=50 \%$

Studies have shown that in a number of cases the level of equivalent stresses on the septum between closely spaced pores and on the contact surfaces of grains and binder exceeds binder's strength. Thus, as the porosity of the diamondiferous layer increases to $50 \%$, the total volume of such sites increases severalfold. It should be noted that as the hardness of the processed material increases, an increase in the number and dimensions of the binder sites is observed, for which a critical stress level is fixed $\left(\sigma_{\mathrm{eq}} \geq 80\right.$ $\mathrm{GPa})$.

This gives grounds for assuming that the stresses that exceed the binder strength can cause local destruction of the highly porous diamondiferous layer. The appearance of microdamage in a binder will facilitate the loss of grains that have completely lost their cutting ability, and will contribute to the renewal of the working surface of the wheel. Thus, the change in the porosity of the diamondiferous layer is one of the most effective control factors of the self-sharpening process of diamond wheels.

\section{Investigation of the structure and properties of porous diamond wheels on a low-melting ceramic binder}

The results of theoretical studies served as the basis for the creation of porous diamond wheels on ceramic binders. Samples of ceramic-matrix diamond-containing composites were prepared using the developed low-melting ceramic binder by a components mixture pressing and subsequent free sintering at a temperature of $620^{\circ} \mathrm{C}$. The porosity of the composite materials obtained was determined by the hydrostatic weighing method: $\mathrm{P}_{\mathrm{V}}=9 \%$ and $\mathrm{P}_{\mathrm{V}}=36 \%$, respectively, for a composite with natural porosity and a highly porous material obtained by forced swelling of binder). The macrostructure of samples of ceramic-matrix diamond-containing composites and the characteristics of pores in the obtained materials are shown in Fig. 7.

The studies of the samples showed that mainly closed spherical pores are present in the composites obtained. In a sample with natural porosity $\left(\mathrm{P}_{\mathrm{V}}=9 \%\right)$ pores are predominately $70-80 \mu \mathrm{m}$; the maximum pore size reached $\sim 125 \mu \mathrm{m}$. In a sample with increased porosity $\left(\mathrm{P}_{\mathrm{V}}=36 \%\right)$, pores with dimensions of 300-350 $\mu \mathrm{m}$ predominate, while the maximum pore size reaches $\sim 500 \mu \mathrm{m}$. The presence of large pores in the diamond-bearing layer of the wheel due to air supply will provide intensive cooling in the contact zone of a diamond-abrasive tools with material to be processed and a workpiece.

The dynamics of wheel working surface change during grinding was studied by laser scanning on a 3D microscope VK-9700K (Keyence). Processing of the obtained data with the use of special software VK Analyzer Plus allowed us to determine the main topographic parameters and to estimate the nature of the change in the $3 \mathrm{D}$ topography of the wheels working surface before and after grinding (Fig. 8). During the experiment, a filter was used to separate the waviness of the macro profile of the working surface of the wheels from the relief of diamond grains above the level of the binder [14]. The results of the studies showed that for different grinding exposures (10 $\mathrm{s}$ and $3 \mathrm{~min}$ ) the value of the support surface $t_{\mathrm{ps}}$ of the wheel with natural porosity (Fig. 8a) differs insignificantly $(0.45 \%$ and $0.6 \%$, respectively). Preservation of topographic parameters indicates that the main wear of the working surface of this sample does not occur due to the loss of grains from the binder but due to the fragile microfracture of grain. It can be assumed that the formation of a worn-out site on the surface of diamond grain causes a local increase in the temperature load and stresses in the grain during grinding. This leads to the appearance of microcracks in grains, that are the starting points of fracture of blunted grains. As it is known, the increase in the cutting properties of diamond wheels is largely determined by the ability of diamond grains to micro-chipping. The new contact surfaces formed in this case act as additional cutting edges, which increases the service life of grains and tools in general. 

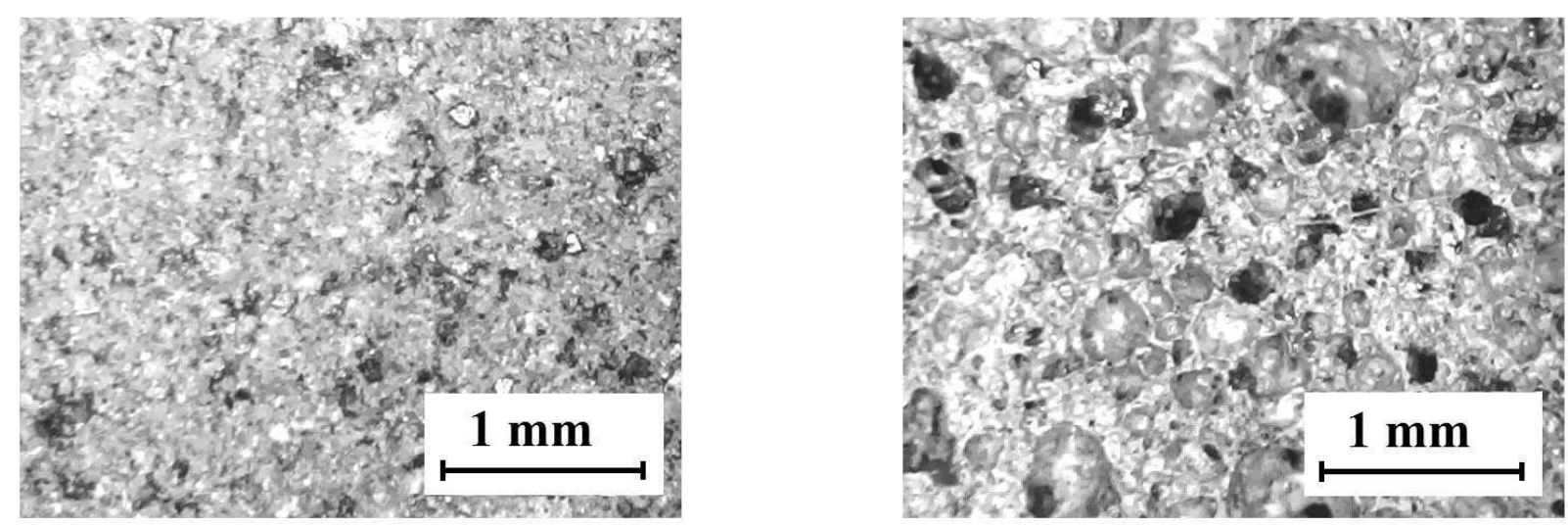

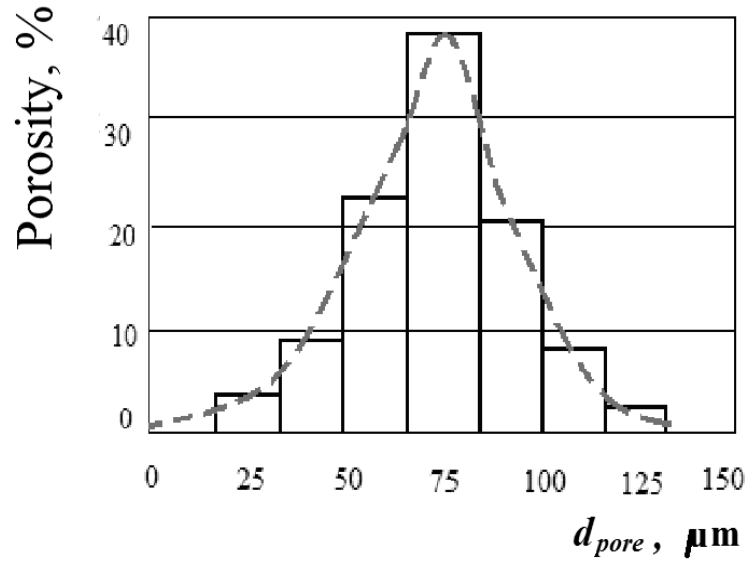

$a$

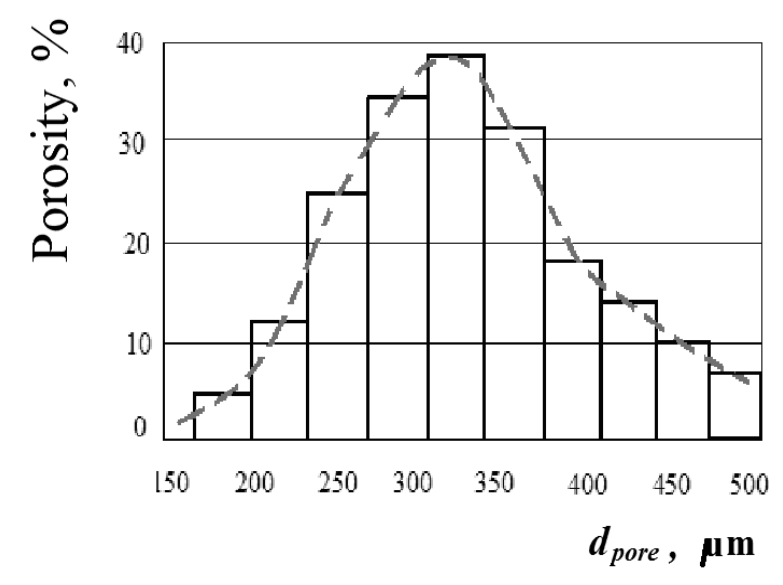

$b$

Fig. 7 The structure of fracture of the diamond wheels and the distribution of pore sizes for samples of composite with different porosities: a) $P_{V}=9 \%$; b) $P_{V}=36 \%$

\section{after 10 seconds of grinding}

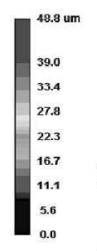

258. 3 200. 0

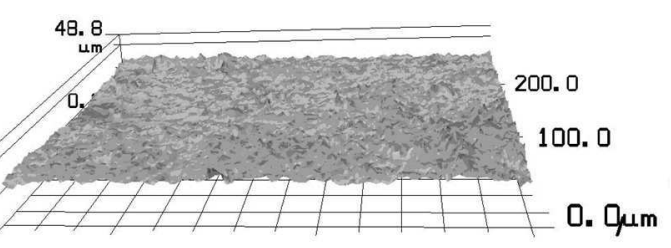

100. 0

$$
\text { 0. } 0 \mu \mathrm{m}
$$

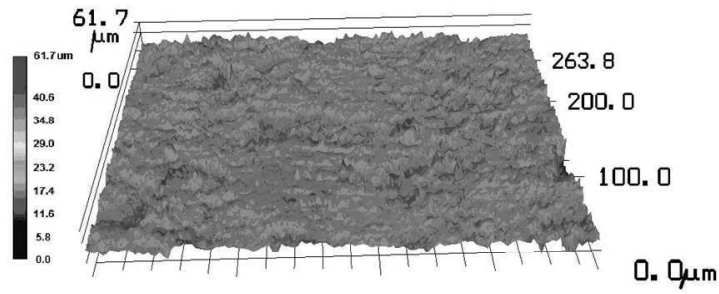

0 um $\quad 100 \quad 200 \quad 300 \quad 351$

after 3 minutes of grinding

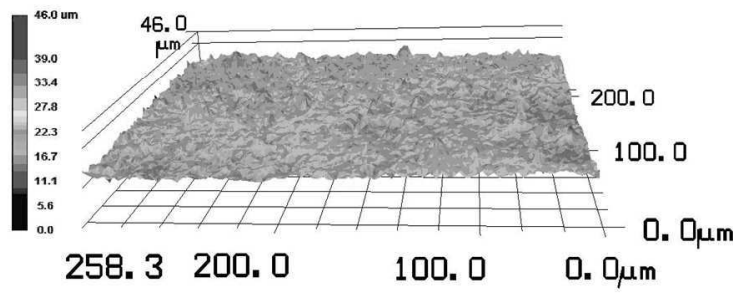

$a$

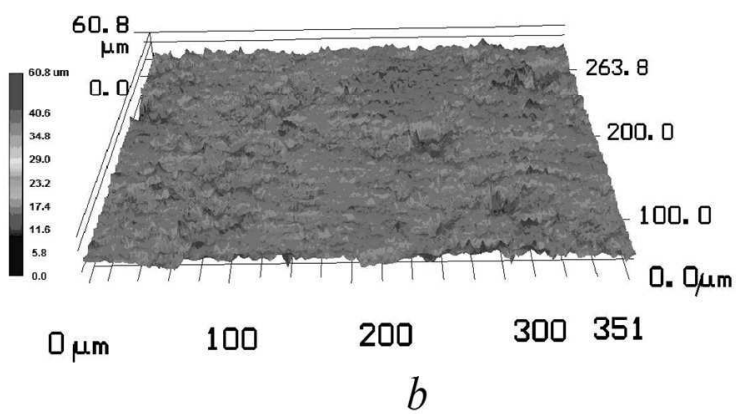

Fig. $83 D$ topography of the diamond wheels working surface after grinding of synthetic polycrystalline diamond: a) sample with $P_{V}=9 \%$; b) sample with $P_{V}=36 \%$ 
The microrelief of a sample of a wheel with increased porosity (Fig. 8b) obtained by forced heaving up of the binder is more developed and has a significant number of sharp cutting edges. Analysis of $t_{p s}$ values along the profile depth of the diamondiferous layer showed that up to a depth of $25 \mu \mathrm{m}$ a monotonic increase of this parameter occurs to $6 \%$, while at the maximum depth of the profile $\mathrm{t}_{\mathrm{ps}}$ varies insignificantly $(0.39-0.55 \%)$. This allows us to assume that when grinding is performed under the indicated conditions, the formation of wear areas on grains is practically not observed due to the microcracking of blunted edges. More noticeable is the change in other topographic parameters of the working surface of the sample, which is probably due to the microfractures of the highly porous binder during grinding. The appearance of microdamage of the binder simplifies the removal of the grains that have completely lost their cutting ability from the working surface of the wheel. Studies have shown that for a wheel with increased porosity of the diamond-bearing layer $\left(\mathrm{P}_{\mathrm{V}}=36 \%\right)$, the best cutting ability is observed at low values of the relative support surface $\left(\mathrm{t}_{\mathrm{ps}}\right)$. Apparently, in this case the specific energy of grinding is minimal and the processing is most effective. The well-developed microrelief of the porous diamond wheel provides additional advantages, such as reduced resistance to chip formation, the exclusion of burns and the reduction of residual stresses in the material after treatment. From these observations allow us to confirm effectiveness of porous diamond wheels formed with the developed low-melting ceramic binder in the grinding of hard-to-work materials.

\section{Conclusions}

With the proposed methodology it is possible to determine the influence of structural, strength, and thermal factors on the stress-strain state of the diamond-bearing layer during the production and operation of diamond grinding wheels at the design stage. Using this approach, a scientifically based selection of the characteristics of porous diamond wheels can be made, taking into account the different processes conditions of the tool life. As a result of micro-level modeling using the developed models, rational characteristics for combinations of constituent elements of ceramic-matrix diamond wheels with natural and increased porosity are determined taking into account the temperature-strength parameters of sintering and grinding of different groups of materials.

The results of theoretical calculations formed the basis for the creation of porous diamond wheels on a lowmelting ceramic binder, which ensures the formation of a diamond-bearing layer at a temperature of $620{ }^{\circ} \mathrm{C}$. The produced samples of diamond wheels demonstrate all the advantages of diamond abrasive tools (durability, excellent cutting ability, high grinding performance and precision of processing, long service life, a wide range of processed materials, including brittle and difficult to process materials). This greatly expands the possible areas of their application in the processing of viscous and plastic steels, cast iron, with intensive processing modes in the operations of profile deep grinding of parts from nickel and titanium alloys, parts from alloy steels with a nitrided surface, or precision grinding, as well as for grinding parts from hardened alloyed steels and sharpening tool without the use of coolant.

\section{References}

[1] TIAN C.C. LI X.K, ZHANG S.B, GUO G.Q, WANG L.P, RONG Y.M. (2018). Study on design and performance of metal-bonded diamond grinding wheels fabricated by selective laser melting (SLM), View Researcher ID and ORCID MATERIALS \& DESIGN Vol. 156 pp.52-61 DOI: 10.1016/j.matdes.2018.06.029 Published: oct 15.2018

[2] LI Z, DING W.F, MA C.Y, XU J.H. (2017). Grinding temperature and wheel wear of porous metalbonded cubic boron nitride superabrasive wheels in high-efficiency deep grinding Proceedings $O f$ The Institution Of Mechanical Engineers Part BJournal Of Engineering Manufacture Volume: 231 Issue: 11 Pages: 1961-1971 DOI: 10.1177/0954405415617928 Published: SEP 2017

[3] YONG-GAI Hou, GUI-Ying Qiaoc, YONG Shanga and oth. (2012). Effect of porosity on the grinding performance of vitrified bond diamond wheels for grinding PCD blades, Ceramic International 2012. Vol. 38. Iss.8. pp. 6215-6220. http: // dx doi.org/ 101016/ceramint.2012304.074

[4] B. STANIEWICZ-BRUDNIK, E. BĄCZEK and G. SKRABALAK. (2015). The New Generation of Diamond Wheels with Vitrified (Ceramic) Bonds Sintering Techniques of Materials, Dr. Arunachalam Lakshmanan (Ed.). InTech, 2015. pp. 53-76.: http://dx.doi.org/10.5772/59503

[5] BAKOŃ A. Structures of diamond tool composites /A. Bakoń, A. Barylski //Mechanik 2017. No 7. pp.540-543.

[6] ONISHI, H; KOBAYASHI, M; TAKATA, A ; ISHIZAKI, K; SHIOURA, T ; KONDO, Y ; TUKUDA, A. (1997). Fabrication of New Porous Metal-Bonded Grinding Wheels by HIP Method and Machining Electronic Ceramics Journal of Porous Materials Volume: 4 Issue: 3 Pages: 187198, DOI: 10.1023/A:1009667017929 Published: SEP 1997

[7] Andrzej SZYMAŃSKI, Andrzej BAKON (1979). The antioxidation coating of diamond and the strengthening of ceramic grinding tools with a glass-ceramic layer as part of the bonding material, Materials Science and Engineering 1979. Vol. $41 \quad$ Iss.2. pp.281-288. https://doi.org/10.1016/0025-5416(79)90149-6

[8] KUNDRÁK, J., FEDOROVICH, V., PYZHOV, I., KLIMENKO, V., KRYUKOVA, N. (2017). Theoretical analysis of the contact area between grinding wheel surface and workpiece in flat face grinding with spindle axis inclination, Manufacturing Technology, 17(2), pp.203-210, 2017 
[9] I. GRABCHENKO, D. V. ROMASHOV, D. O. FEDORENKO and oth. (2014). Simulation of the effect of sintering on the integrity of diamond grains in grinding wheels, Nanotechnology Perceptions 2014. No 10(1). pp.42-53.

[10] J.Y. HOWE, L. E. JOLES, CORMACK A.N. (2001). The oxidation of diamond School of Ceramic Engineering and Materials Science, Alfred University 2001. pp.1-5.

[11] TIAN C.C, LI X.K, ZHANG S.B, GUO G.Q, ZIEGLER S, SCHLEIFENBAUM J.H, WANG L.P, RONG Y.M. (2019). Porous structure design and fabrication of metal-bonded diamond grinding wheel based on selective laser melting (SLM) International Journal Of Advanced Manufacturing Technology Volume: 100 Issue: 5-8 Pages: 14511462 Special Issue: SI DOI: 10.1007/s00170-0182734-y, Published: FEB 2019

[12] Marcio Carneiro Garcia ROSAA, Matheus Paes PEÇANHAA, Marcello FILGUEIRAA (2015). Thermal Damage in Diamonds: the Protective Effect of Titanium Coating Materials Research, 2015. vol.18. No.4. P. 683-689: http://dx.doi.org/10.1590/1516-1439.299414

[13] GRABCHENKO, A., FEDOROVICH, V., PYZHOV, I., KUNDRÁK, J. (2014). 3D simulation of vibrating diamond grinding, Manufacturing Technology, 14(2), pp. 153-160, 2014

[14] MAMALIS, A. G., GRABCHENKO A. I., FEDOROVICH V. A., KUNDRAK J. (2012). Simulation of effects of metal phase in a diamond grain and bonding type on temperature in diamond grinding. The International Journal of Advanced
Manufacturing Technology, 58/2012 pp.195-200 DOI: $10.1007 / \mathrm{s} 00170-011-3382-7$

[15] A.I. GRABCHENKO, D.V. ROMASHOV, D.O. FEDORENKO, V.A. FEDOROVICH, A.G. MAMALIS, J. KUNDRAK (2012). Prevention of manufacturing defects of diamond composite materials by simulating the process at the micro level Nanotechnology Perceptions. 8 2012, pp. 171180.

[16] MAMALIS AG, GRABCHENKO AI, FEDOROVICH VA, KUNDRÁK J. (2009). Methodology of 3D simulation of processes in technology of diamond-composite materials, International Journal Of Advanced Manufacturing Technology, Volume: 43, Issue: 11-12, pp.1235-1250, DOI: 10.1007/s00170-008-1802-0 Published: 2009

[17] TIAN C.C, LI X.K, LI H.Y, GUO G.Q, WANG L.P, RONG Y.M. (2018). The effect of porosity on the mechanical property of metal-bonded diamond grinding wheel fabricated by selective laser melting (SLM), Materials Science And Engineering A-Structural Materials Properties Microstructure And Processing, Vol.: 743 pp.697706, DOI: 10.1016/j.msea.2018.11.138 Published: JAN 162019

[18] C. C. WANG, F. L. ZHANG, J. S. PAN, J. B. MAO and oth. (2017). An experimental study on preparation of vitrified bond diamond grinding wheel with hollow spherical corundum granules as pore former, The International Journal of Advanced Manufacturing Technology. 2017. Vol. 93. Iss. 1-4. pp.595-603. 